Citation: Viquez K et al. (2019)

"The Use of CardioMEMS in Dialysis Patients with Heart Failure."

The VAD Journal, 7. doi: https://doi.org/10.13023/VAD.201 $\underline{9.07}$

Editor-in-Chief: Maya Guglin, University of Kentucky

Received: June 1, 2019

Accepted: June 14, 2019

Published: June 15, 2019

(c) 2019 The Author(s). This is an open access article published under the terms of the Creative Commons Attribution-

NonCommercial 4.0 International License

(https://creativecommons.org/lice nses/by-nc/4.0/), which permits unrestricted non-commercial use, distribution, and reproduction in any medium, provided that the original author(s) and the publication source are credited.

Funding: Not applicable

Competing interests: Not applicable

\section{The Use of CardioMEMS in Dialysis Patients with Heart Failure}

\author{
Karolina Viquez ${ }^{1^{*}}$, Peggy Hardesty ${ }^{2}$, Mohamed Elyamny ${ }^{3}$, Karim \\ Fahmy $^{3}$, Amr Elhusseini ${ }^{3}$, and Maya Guglin ${ }^{2}$ \\ ${ }^{1}$ Department of Internal Medicine, University of Kentucky \\ 2 Division of Cardiovascular Disease, Gill Heart Institute, University of Kentucky \\ ${ }^{3}$ Division of Nephrology, University of Kentucky, Lexington, KY \\ *Corresponding author: karolina.viquez@uky.edu
}

Keywords: CardioMEMS, dialysis, heart failure

\begin{abstract}
In patients with chronic kidney disease (CKD) and heart failure (HF), volume overload is a major problem. Removal of fluid during the dialysis treatment is the cornerstone management in these conditions, but assessing the amount of volume that should be removed is a challenge since physical exam findings are not accurate. Ambulatory pulmonary artery (PA) pressure measurement is a promising tool in HF that potentially could be used as well in CKD population, monitoring volume status changes and allowing a prompt intervention such as increasing or decreasing the volume of ultrafiltration. We presented two cases of patients with CKD, HF and CardioMEMS.
\end{abstract}




\section{Introduction}

Chronic kidney disease (CKD) affects $13.6 \%$ of the US population ${ }^{1}$. A significant proportion of these patients progresses to end stage renal disease (ESRD) requiring renal replacement therapy or renal transplantation. Cardiovascular disease remains the most common cause of mortality in these patients ${ }^{2}$.

Volume overload is a major problem in patients with kidney failure especially in those with an underlying heart disease ${ }^{3}$. It is not uncommon for dialysis patients to develop signs and symptoms of volume overload. Hence, removal of fluid during the dialysis treatment, also known as ultrafiltration, is the cornerstone of volume management in advanced-stage CKD ${ }^{4}$.

Previous studies have revealed that excessive inter-dialytic weight gain is associated with adverse clinical outcomes ${ }^{5-9}$, finding it to be an independent predictor of all-cause and cardiovascular mortality in dialysis patients ${ }^{5}$. In addition, accumulating evidence shows that inter-dialytic weight gain is significantly associated with left ventricular hypertrophy and risk of cardiovascular mortality ${ }^{10,11}$. It could be helpful to prevent excessive inter-dialytic weight gain for improving clinical outcomes in incident dialysis patients ${ }^{12}$.

A main challenge related to ultrafiltration is the assessment of the volume status and the required intra-dialytic fluid removal. Target weight in dialysis patients is the most commonly used method, and it is defined as the lowest tolerable body weight not associated with symptoms of hypovolemia ${ }^{13,14}$. However, in many circumstances it might be impossible to determine the ideal target weight based on clinical findings. Furthermore, this routine assessment has not contributed to reducing cardiovascular mortality in dialysis patients, which is ultimately one of the main long-term goals of renal replacement therapy.

CardioMEMS system (Abbott, Abbott Park, IL) is a pressure sensor implanted into the pulmonary artery (PA) for remote monitoring of PA pressure in ambulatory patients. Pulmonary arterial pressure-guided heart failure (HF) management using CardioMEMS was tested in the CHAMPION trial (CardioMEMS Heart Sensor Allows Monitoring of Pressure to Improve Outcomes in NYHA (New York Heart Association) functional Class III Heart Failure Patients) and resulted in substantial reductions of hospitalizations for $\mathrm{HF}^{15}$. Testing of CardioMEMS in dialysis patients with HF seems logical, promising and has the potential of optimizing volume status and reducing cardiovascular complications.

Herein we are reporting on two HF patients who had CardioMEMS and were later started on dialysis. Interestingly, one of them was switched from hemodialysis to peritoneal dialysis.

\section{Methods}

We retrospectively reviewed medical records of the two patients and collected the data on their demographics, clinical condition, medications, results of right heart catheterization, and echocardiographic reports. Also, we extracted the following 
data from the hemodialysis records: pre-and post-dialytic weight, systemic blood pressure and heart rate, and the volume of fluid removed per session.

We then collected CardioMEMS's data, including PA systolic, diastolic, and mean pressure. Subsequent information on 60 CardioMEMS readings before the beginning of hemodialysis and equal number of readings on hemodialysis were collected. On the patient who was later switched to peritoneal dialysis, the readings of CardioMEMS while she was on peritoneal dialysis were collected as well. Mean PA pressures before and after the beginning of hemodialysis and on peritoneal dialysis were compared for each patient using Student's t-test.

\section{Case 1. Heart Failure with Preserved Ejection Fraction}

65-year-old Caucasian female with history of type II diabetes, hypertension, CKD, hypothyroidism, hepatitis C, liver cirrhosis, had NYHA class III diastolic HF. Echocardiogram showed left ventricular ejection fraction $>55 \%$, normal right ventricular systolic function, right ventricular systolic pressure $40-50 \mathrm{mmHg}$, normal atrial and ventricular size (left ventricular end diastolic dimension $4.1 \mathrm{~cm}$ ) and no valvular abnormalities. Cardiac catheterization demonstrated the following pressures: right atrium $11 \mathrm{mmHg}$, right ventricle $50 / 11 \mathrm{mmHg}, \mathrm{PA} 50 / 16 \mathrm{mmHg}$ (mean $30 \mathrm{mmHg}$ ), pulmonary capillary wedge pressure $30 \mathrm{mmHg}$, cardiac output 7.0 L/min and cardiac index 3.6 L/min/ $/ \mathrm{m}^{2}$. CardioMEMS was implanted in November 2016. Her medications included metolazone $10 \mathrm{mg}$ once a day, bumetanide $2 \mathrm{mg}$ twice a day, carvedilol $12.5 \mathrm{mg}$ twice a day, isosorbide mononitrate $60 \mathrm{mg}$ once a day, hydralazine $100 \mathrm{mg}$ three times a day, cinacalcet $30 \mathrm{mg}$ once a day, insulin and levothyroxine.

Patient had declining kidney function, and intermittent hemodialysis (HD) was initiated via a tunneled catheter in September 2018. Patient received 3.5 hour HD sessions regularly 3 times a week with an average blood flow rate of 400 $\mathrm{ml} / \mathrm{minute}$ and a fluid removal of 2 liters aiming a target weight of $78 \mathrm{~kg}$.

Patient's vital signs and laboratory values are listed in Table 1. There was no any need to early terminate dialysis for hemodynamic instability or arrhythmias but she had complained of bad cramps with any attempt of taking take more fluid off.

Table 1. Patient 1: Clinical parameters before and after dialysis session

\begin{tabular}{|l|l|l|l|}
\hline & Before HD session & After HD session & $P$ \\
\hline Weight, kg & Mean \pm SD & Mean \pm SD & \\
\hline Systolic BP, mmHg & $78.2 \pm 0.8$ & $76.8 \pm 0.6$ & $<0.0001$ \\
\hline Diastolic BP, mmHg & $159.2 \pm 30.2$ & $149.1 \pm 27.5$ & 0.2 \\
\hline Heart rate, beats per minute & $68.6 \pm 11.5$ & $64.5 \pm 14.7$ & 0.3 \\
\hline Net volume removed, L & $60.2 \pm 8.2$ & $57.7 \pm 4.7$ & 0.2 \\
\hline
\end{tabular}

BP- blood pressure

HD - hemodialysis

SD - standard deviation 
Her dialysis adequacy measures were optimal (an average KT/V of 1.5 , where $\mathrm{K}$ is the dialyzer clearance of urea, $\mathrm{T}$ stands for dialysis time and $\mathrm{V}$ is the volume of distribution of urea).

The patient was switched to continuous cyclic peritoneal dialysis (PD) through a Tenckhoff PD catheter in January 2019 using four cycles with a total dialysate volume of $8800 \mathrm{ml}$ over 8.5 hours. Her average KT/V was 2.0. Her PA pressure by CardioMEMS increased after initiation of the HD but decreased after PD was established (Figure 1, Table 2).

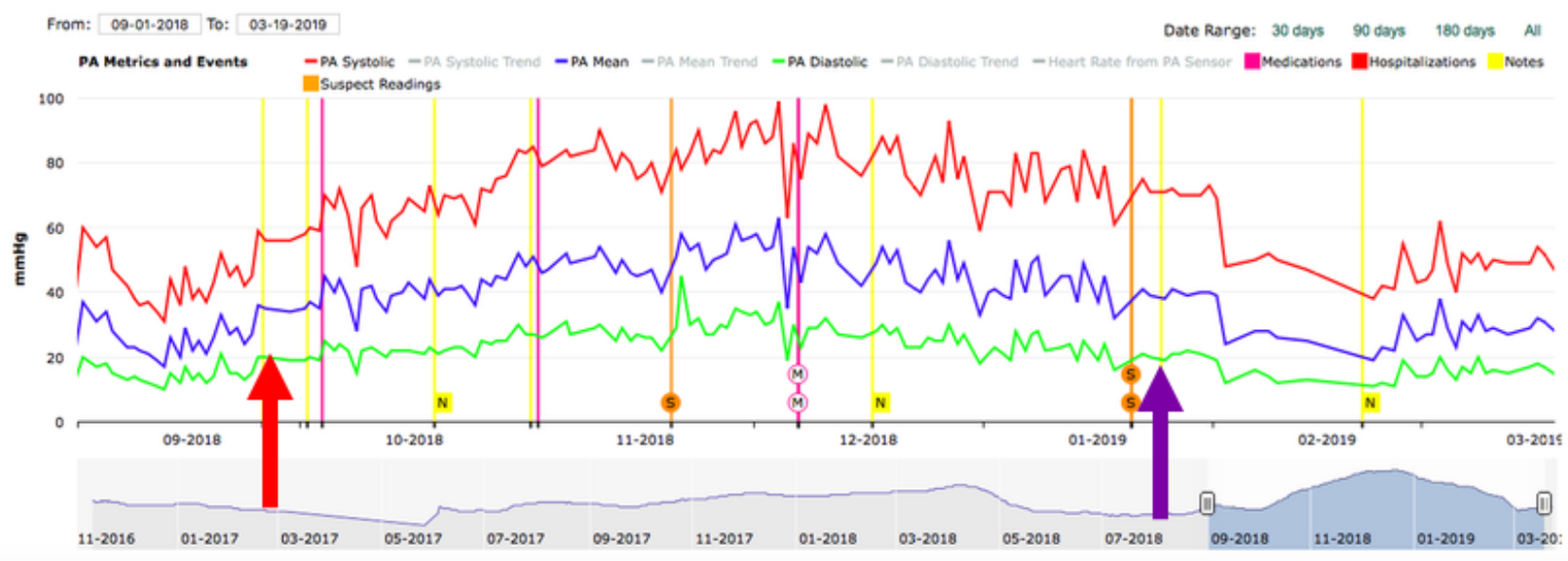

Figure 1: PA pressures. Red arrow indicates when hemodialysis was started and the purple arrow indicates when peritoneal dialysis was initiated.

Table 2: Case 1: PA pressures before HD (60 consecutive readings), on HD (60 consecutive readings), and on PD (54 consecutive readings).

\begin{tabular}{|l|l|l|l|l|}
\hline & $\begin{array}{l}\text { Before HD } \\
(\text { Mean } \pm \text { SD })\end{array}$ & $\begin{array}{l}\text { On HD } \\
(\text { Mean } \pm \text { SD })\end{array}$ & $\begin{array}{l}\text { On PD } \\
(\text { Mean } \pm \text { SD })\end{array}$ & P Value \\
\hline PA pressure, mmHg & & & & \\
\hline Systolic & $43.8 \pm 7.3$ & $74.9 \pm 11.3$ & $59.6 \pm 13.7$ & $<0.0001$ \\
\hline Diastolic & $14.8 \pm 3.1$ & $25.8 \pm 5.2$ & $18.3 \pm 4.3$ & $<0.0001$ \\
\hline Mean & $26.1 \pm 5.2$ & $45.6 \pm 7.5$ & $34.3 \pm 8.1$ & $<0.0001$ \\
\hline
\end{tabular}

HD: hemodialysis

PA: pulmonary artery

PD: peritoneal dialysis

SD: standard deviation

Note: The $\mathrm{P}$ value is same for all comparisons (before dialysis versus $\mathrm{HD}$, before dialysis versus $\mathrm{PD}$, and on $\mathrm{HD}$ versus on $\mathrm{PD})$. 


\section{Case 2. Heart Failure with Reduced Ejection Fraction}

73-year-old Caucasian male with history of type II diabetes, hypertension, and CKD had NYHA class III systolic HF secondary to ischemic cardiomyopathy. Echocardiogram showed decreased left ventricular ejection fraction $<25 \%$, with a dilated left ventricle (end diastolic dimension of $6.4 \mathrm{~cm}$ ), right ventricular systolic pressure $94 \mathrm{mmHg}$, and moderate mitral regurgitation. Right side heart catheterization demonstrated the following pressures: right atrium $11 \mathrm{mmHg}$, right ventricle $61 / 13 \mathrm{mmHg}$, PA $67 / 26 \mathrm{mmHg}$ (mean $43 \mathrm{mmHg}$ ), pulmonary capillary wedge pressure $46 \mathrm{mmHg}$, cardiac output $5.7 \mathrm{~L} / \mathrm{min}$ and cardiac index 2.8 $\mathrm{L} / \mathrm{min} / \mathrm{m}^{2}$. CardioMEMS was implanted in October 2016.

Patient had declining kidney function. A right upper arm arteriovenous fistula was placed, and intermittent HD was initiated in July 2018. Patient received 4 hours HD session regularly 3 times a week with an average blood flow rate of $400 \mathrm{ml} / \mathrm{min}$ and a fluid removal of 3.5-4.5 liters aiming a target weight of $89 \mathrm{~kg}$ (Table 3). There was no need to early terminate any of the dialysis sessions for hemodynamic instability or arrhythmia.

Table 3: The Mean \pm SD of clinical parameters in case number 2.

\begin{tabular}{|l|l|l|l|}
\hline & $\begin{array}{l}\text { Before HD session } \\
(\text { Mean } \pm \text { SD })\end{array}$ & $\begin{array}{l}\text { After HD session } \\
(\text { Mean } \pm \text { SD })\end{array}$ & P Value \\
\hline Weight, kg & $92.4 \pm 1.5$ & $89.2 \pm 1.5$ & $<0.0001$ \\
\hline Systolic BP, mmHg & $122.5 \pm 11.0$ & $116.3 \pm 12.2$ & 0.007 \\
\hline Diastolic BP, mmHg & $68.1 \pm 7.4$ & $68.0 \pm 9.6$ & 0.9 \\
\hline Heart rate, beats per minute & $67.5 \pm 5.3$ & $61.2 \pm 90$ & $<0.0001$ \\
\hline Net volume removed, L & & $3.2 \pm 1.2$ & \\
\hline
\end{tabular}

BP: blood pressure

HD: hemodialysis

SD: standard deviation

His dialysis adequacy measures were optimal (an average KT/V of 1.7) His medications included carvedilol 25mg twice a day, hydralazine $100 \mathrm{mg}$ three times a day, Insulin and glimepiride. His PA pressures readings by CardioMEMS gradually declined after initiation of dialysis (Figure 2, Table 4).

The volume of fluid removed per HD session was significantly greater in the second patient $(3.2 \pm 1.2 \mathrm{~L}$ vs $1.45 \pm 0.7 \mathrm{~L}, \mathrm{P}<0.0001)$. When we indexed the net volume removed for pre-dialysis weight, the difference persisted $(0.003 \pm 0.013 \mathrm{vs}$ $0.019 \pm 0.009, P<0.0001)$. 


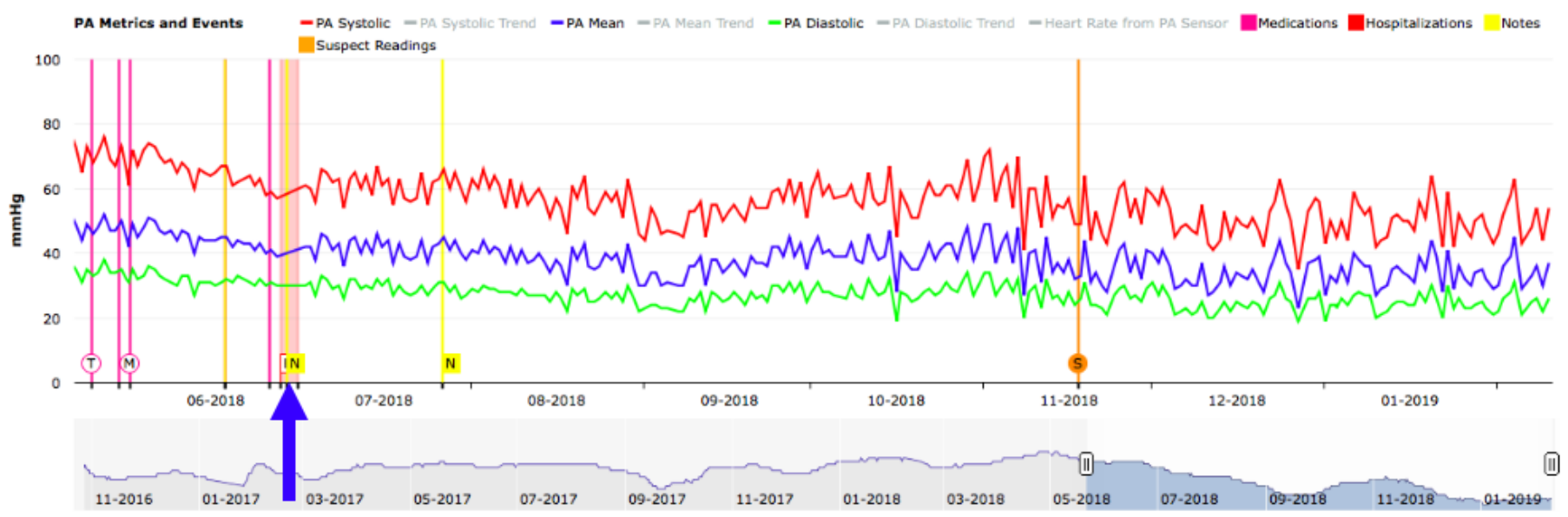

Figure 2: PA pressures. Arrow indicates the time of hemodialysis initiation.

Table 4: Case 2: PA pressure before HD (60 consecutive readings), and on HD (60 consecutive readings)

\begin{tabular}{|l|l|l|l|}
\hline & $\begin{array}{l}\text { Before HD } \\
(\text { Mean } \pm \text { SD })\end{array}$ & $\begin{array}{l}\text { On HD } \\
(\text { Mean } \pm \text { SD })\end{array}$ & P Value \\
\hline PA pressure, mmHg & & & \\
\hline Systolic & $67.6 \pm 4.9$ & $57.7 \pm 6.0$ & $<0.0001$ \\
\hline Diastolic & $32.3 \pm 2.3$ & $27.9 \pm 2.9$ & $<0.0001$ \\
\hline Mean & $45.5 \pm 3.4$ & $39.2 \pm 4.5$ & $<0.0001$ \\
\hline
\end{tabular}

HD: hemodialysis

PD: peritoneal dialysis

SD: standard deviation

\section{Discussion}

Heart failure is a chronic condition, with the symptoms resulting from fluid retention due to inadequate cardiac output and elevated cardiac filling pressures ${ }^{3}$. Chronic volume overload in both HF and CKD results in left ventricular hypertrophy, dilatation and cardiac dysfunction, with or without decrease in left ventricular ejection fraction, increasing the risk of cardiovascular mortality ${ }^{16}$. Reversing hypervolemia remains the key management strategy in renal disease patients with $\mathrm{HF}^{3}$. In cases where hypervolemia is not controlled, dialysis could be used as an alternative. A previous prospective randomized study compared ultrafiltration and intravenous diuretics in patients hospitalized for acute decompensated HF and reported more fluid removal and decreased rehospitalization rates in those 
undergoing ultrafiltration ${ }^{18}$. These results could be extrapolated to show the potential value of extracorporeal ultrafiltration as a treatment for HF in long-term dialysis patients.

The CHAMPION Trial demonstrated the utility of PA pressure guided HF management strategy using a wireless implantable hemodynamic monitoring system. Patients managed with the addition to ambulatory hemodynamic monitoring were compared with patients on HF management based on practice guidelines only. CardioMEMS' patients showed substantial reductions in hospital admissions for HF, irrespective of left ventricular pump function. This is probably because the PA pressure guided HF management facilitates timely recognition of incipient hypervolemia and appropriate modification of medical treatment. ${ }^{15}$

We described two cases of patient with advanced CKD, HF and cardioMEMS, patients were identified to have elevated PA pressures even after receiving HD. A main challenge related to ultrafiltration in dialysis patients is the assessment of the required magnitude and frequency of fluid removal ${ }^{5}$. Dry weight is one of the most common methods used, but given that clinical findings are imprecise, this method cannot accurately predict the ultrafiltration volume ${ }^{12}$. Not uncommonly patients develop manifestations of hypovolemia during and after dialysis. It is well established that excessive volume removal is associated with repeated episodes of myocardial stunning developing regional fixed left ventricular dysfunction and worsening $\mathrm{HF}^{19}$. On the other hand, insufficient fluid removal is also associated with volume overload, deteriorating HF and worsening pulmonary hypertension. Another challenging situation is choosing the dialysis modality. The notion is continuos dialysis therapies are more hemodynamically tolerable and associated with less myocardial stunning. This is probably because of gentle fluid removal ${ }^{20}$, 21.

In our case number 1 , the patient PA pressures, already elevated, worsened while on HD but significantly improved after she was switched to PD. In the two cases we presented, starting of dialysis clearly resulted in change of their PA pressures. In the first case of HF with preserved ejection fraction and small left ventricle, pulmonary pressures significantly increased. In the second case of HF with reduced ejection fraction and enlarged left ventricle, PA pressures decreased. In non-dialysis patients with HF, volume status is primarily controlled with loop diuretics, and the effect is dose-dependent. In HD, fixed volume of fluid is removed three times a week. In the first patient, the amount of fluid removal could not be increased on HD because she experienced symptoms of hypovolemia. In HF with preserved ejection fraction small changes in intravascular volume produce marked changes in intra-cardiac pressures ${ }^{22}$, possibly due to small and noncompliant left ventricle.

On the other hand, the patient with large ventricle tolerated higher volumes of fluid removed per HD session. The amount of fluid removal per HD session was lower in the first compared to the second patient, both in absolute values and indexed for body weight. The first patient's hemodynamics much improved on PD with more gentle and gradual fluid removal. This might be because PD allows more time for the heart to accommodate intravascular volume changes as it is more slow/chronic 
dialysis therapy compared to HD. Of note, hemodynamic response to dialysis in these two patients demonstrates that approach to chronic renal replacement therapy may differ in patients with HF with reduced and preserved ejection fraction.

\section{Conclusions}

Management of fluid status is a significant challenge in dialysis patients with HF. Up to date there is no clear recommendation of how to determine the appropriate amount of ultrafiltration. Remote ambulatory monitoring of PA pressures helps in guiding the amount of fluid removal in this patient population. Testing CardioMEMS in this clinical setting is promising since it accurately predicts the volume status. Ambulatory monitoring of volume status may help with decision making on the modality of dialysis. More studies are needed in order to establish the utility of using this device in improving clinical outcome. 


\section{References}

1. United States Renal Data System. 2015 USRDS Annual Data Re- port: Epidemiology of Kidney Disease in the United States. Bethesda, MD: National Institutes of Health; 2015. Accessed at www .usrds.org/2015/view/Default.aspx on February 20, 2019.

2. Wright J, Hutchison A. Cardiovascular disease in patients with chronic kidney disease. Vasc Health Risk Manag. 2009; 5:713-22.

3 . Tuegel C, Bansal N. Heart failure in patients with kidney disease. Heart. 2017; 103:1848-53.

4. Chou JA, Kalantar-Zadeh K. Volume Balance and Intradialytic Ultrafiltration Rate in the Hemodialysis Patient. Curr Heart Fail Rep. 2017; 14:421-427.

5. Kalantar-Zadeh K, Regidor DL, Kovesdy CP, Van Wyck D, Bunnapradist S, Horwich TB, Fonarow GC. Fluid retention is associated with cardiovascular mortality in patients undergoing long-term hemodialysis. Circulation. 2009; 119: $671-9$.

6. Leggat JE Jr, Orzol SM, Hulbert-Shearon TE, Golper TA, Jones CA, Held PJ, Port FK. Noncompliance in hemodialysis: predictors and survival analysis. Am J Kidney Dis. 1998; 32: 139-45.

7. Saran R, Bragg-Gresham JL, Rayner HC, Goodkin DA, Keen ML, Van Dijk PC, Kurokawa K, Piera L, Saito A, Fukuhara S, Young EW, Held PJ, Port FK. Nonadherence in hemodialysis. Associations with mortality, hospitalization, and practice patterns in the DOPPS. Kidney Int. 2003; 64: 254-62.

8. Holmberg B, Stegmayr BG. Cardiovascular conditions in hemodialysis patients may be worsened by extensive interdialytic weight gain. Hemodial Int. 2009; 13: 27-31.

9. Flythe JE, Curhan GC, Brunelli SM: Disentangling the ultrafiltration ratemortality association. The respective roles of session length and weight gain. Clin J Am Soc Nephrol. 2013; 8: 1151-61.

10. Koc Y, Unsal A, Kayabasi H, Oztekin E, Sakaci T, Ahbap E, Yilmaz M, Akgun AO. Impact of volume status on blood pressure and left ventricle structure in patients undergoing chronic hemodialysis. Ren Fail. 2011; 33: 377-81.

11. Zoccali C, Benedetto FA, Mallamaci F, Tripepi G, Giacone G, Stancanelli $B$, Cataliotti A, Malatino LS. Left ventricular mass monitoring in the follow-up of dialysis patients: prognostic value of left ventricular hypertrophy progression. Kidney Int. 2004; 65: 1492-8.

12. Lee MJ1, Doh FM, Kim CH, Koo HM, Oh HJ, Park JT, Han SH, Yoo TH, Kim YL, Kim YS, Yang CW, Kim NH, Kang SW. Interdialytic weight gain and cardiovascular outcome in incident hemodialysis patients. Am J Nephrol. 2014; 39 (5): 427-35.

13. Wizemann V, Schilling M. Dilemma of assessing volume state -the use and the limitations of a clinical score. Nephrol Dial Transplant. 1995; 10:2114-7.

14. Charra B. Fluid balance, dry weight, and blood pressure in dialysis," Hemodialysis Int. 2007;11:21-31.

15. Abraham WT, Adamson PB, Hasan A, Bourge RC, Aaron MF, Costanzo MR, Stevenson MW, Strickland W, Neelagaru S, Raval N, Krueger S, Weiner S, Shavelle D, Jeffries B, Yadav JS; CHAMPION Trial Study Group. Wireless pulmonary artery hemodynamic monitoring in chronic heart failure: a randomized controlled trial. Lancet. 2011; 377:658-66. 
16. Segall L., Nistor I., Covic A. Heart failure in patients with chronic kidney disease: A systematic integrative review. Biomed Res Int. 2014; 2014:937398. 17. Felker GM, O'Connor CM, Braunwald E, Heart Failure Clinical Research Network Investigators. Loop diuretics in acute decompensated heart failure: necessary? Evil? A necessary evil? Circ Heart Fail. 2009;2:56-62.

18. Costanzo MR, Guglin ME, Saltzberg MT et al. Ultrafiltration versus intravenous diuretics for patients hospitalized for acute decompensated heart failure. J Am Coll Cardiol. 2007; 49:675-83.

19. Mahmoud H, Forni LG, Mclntyre CW, Selby NM. Myocardial stunning occurs during intermittent haemodialysis for acute kidney injury. Intensive Care Med. 2017;43:942-944.

20. Wang IK, Lin CL, Sung FC. Lower risk of de novo congestive heart failure in peritoneal dialysis patients compared with hemodialysis patients. Int $\mathrm{J}$ Cardiol. 2017; 229:123.

21. Puttagunta H, Holt SG. Peritoneal dialysis for heart failure. Perit Dial Int. 2015; 35:645-9

22. Zile MR, Baicu CF, Gaasch WH. Diastolic heart failure-abnormalities in active relaxation and passive stiffness of the left ventricle. $\mathrm{N}$ Engl $\mathrm{J}$ Med.

2004;350(19):1953-9. 